\title{
Evaluation of Effects of Varicocele Repair on Seminal Parameters in Cases of Clinical and Subclinical Varicocele - A Two Year Study
}

\author{
Suresh Kumar ${ }^{1}$, Kishore Kumar Markapuram², B Naveen Kumar ${ }^{3}$, Ramakrishna Baru ${ }^{4}$, Sreeram Satish ${ }^{5}$ \\ ${ }^{1}$ Assistant professor, Department of Radiology, ${ }^{2}$ Associate Professor, Department of General Surgery, ${ }^{3}$ Professor. Department of Radiology, \\ ${ }^{4}$ Professor and HOD, Department of Radiology, ${ }^{5}$ Professor and HOD, Department of General Surgery, Narayana Medical College, \\ Chinthareddypalem, Nellore, Andhra Pradesh, India
}

Corresponding author: Dr Kishore Kumar Markapuram, Associate Professor, Department of General Surgery, Narayana Medical College, Chinthareddypalem, Nellore, Andhra Pradesh, India

DOI: 10.21276/ijcmsr.2018.3.2.24

How to cite this article: Suresh Kumar, Kishore Kumar Markapuram, B Naveen Kumar, Ramakrishna Baru, Sreeram Satish. Evaluation of effects of varicocele repair on seminal parameters in cases of clinical and subclinical varicocele - a two year study. International Journal of Contemporary Medicine Surgery and Radiology. 2018;3(2):B97-B101.

\section{A B S T R A C T}

Introduction: The causes of Male infertility are multifactorial and varicocele occupies a significant position with a prevalence of $19-41 \%$ in cases of primary infertility and $45-81 \%$ among cases of secondary infertility. Several studies have shown a significant correlation on varicocele and altered semen parameters. The aim of present study was to evaluate the effects of surgical varicocelectomy in cases of clinical and subclinical varicocele on the seminal parameters with a special focus on the sperm morphology, concentration and motility of the sperms.

Material and methods: A prospective cross sectional study for a period of two years was conducted and all patients with clinical and subclinical varicoceles (diagnosed radiologically) were included and varicocelectomy was done. Pre and postoperative semen samples were collected and evaluated for alterations in semen concentration, motility and morphology of sperm. The data was analyzed with SPSS software version 20 for windows 10 and level of significance was assessed by paired $t$ test, by considering $p$ value less than 0.05 .

Results: 125 cases were included and 18-25 years was the major age group and left sided varicocele was commonest. 99 clinical and 26 subclinical varicoceles were identified and corrected by microsurgical approach in all cases. In our study a highly significant increase in sperm count was noticed in clinical and subclinical varicocele after varicocelectomy, but there was no significant difference in sperm morphology in both the groups.

Discussion: To conclude our study demonstrated a clear increase in the semen parameters, i.e., sperm morphology, concentration and motility in clinical and subclinical cases of varicocele after surgical repair.

Key words: Varicocele, Subclinical Varicocele, Varicocelectomy, Seminal Parameters.

\section{INTRODUCTION}

Infertility is a concerning and emerging threat among couples trying to conceive with an incidence of $10-15 \%$, and male infertility accounting to $50 \%$ among these cases. Although the cause of male infertility is multifactorial, varicocele occupies a significant position with a prevalence of $19-41 \%$ in cases of primary infertility and $45-81 \%$ among cases of secondary infertility. ${ }^{1}$ Varicocele is defined as abnormal dilatation and tortuosity of pampiniform plexus of testicular veins that drain the testis. Despite high frequency the exact mechanism on how varicocele affects the fertility is still a controversial issue and few explained reasons include, increased scrotal temperature, reflux of metabolites from the kidney and adrenal gland, decreased volume of blood flow and anoxia. Varicocele demonstrated clinically are defined as clinical varicocele and graded whereas varicocele detected by Doppler ultrasound only but not clinically are called as subclinical varicocele. Varicoceles are detected after puberty and their incidence among common men is around 11$15 \%$. Several studies have shown a significant correlation on varicocele and altered semen parameters. A who report in 1992 has documented a decreased testicular volume and low sperm count per ejaculate among men with varicocele. ${ }^{3}$ Among the men with varicoceles, most of varicoceles are present on left side (90\%) with $1.10 \%$ bilateral and $0.2 \%$ an isolated right sided varicocele. Varicocele is most common surgically correctable cause of male infertility. However the approaches for correction are many including surgical ligation of spermatic vein, laparoscopic procedures, or different embolization techniques. The post effects of varicocele repair on patterns of seminal patterns remains controversial. Most of the studies pointed out significant alteration sin sperm morphology, motility and concentration. However 
few studies report no significant changes in the seminal parameters. Treatment of cases with subclinical varicocele remains controversial. Few of the studies were conducted on the effects of surgical repair on seminal parameters in cases of subclinical varicocele. A significant increase in sperm density and total motile count were increased after 1 year in cases of subclinical varicocele in few studies. The variable results in different studies may be due to differences in the size of the study group, type of surgical procedure employed and different diagnostic modalities employed.

Hence the present study was done to evaluate the effects of surgical varicocelectomy in cases of clinical and subclinical varicocele on the seminal parameters with a special focus on the sperm morphology, concentration and motility of the sperms.

\section{MATERIAL AND METHODS}

The present prospective cross sectional study was conducted at a tertiary care hospital of south India for a period of two years from January 2106 to December 2017 at Department of general surgery in association with Department of Radiology. The study was approved by the institutional ethical committee and all the study was conducted ad per the guidelines and protocol of the committee. All the patients attending the OPD of department of General surgery with history of scrotal swellings and cases referred from infertility clinic with history of primary infertility and with abnormal seminal analysis were included in the study.

All the cases were thoroughly examined clinically with collection of all data eg: clinical history, age etc and the data was entered in a separate predesigned questionnaire sheet. Cases with diagnosed varicocele were graded and the semen was collected and sent for analysis. All the cases in the study were subjected to scrotal color Doppler Ultrasonography and cases of subclinical varicocele were diagnosed based on Ultrasonography (Scrotal).A written informed consent was obtained from all the cases included in the study. Cases with history of genital tract infections, recurrent varicocele, systemic diseases which can affect the semen parameters were excluded from the study. The surgical approach in management of varicocele was varicocelectomy by inguinal approach. All the cases were thoroughly followed for a period of six months further and semen samples were collected postoperatively for analysis. The cases were followed for any recurrences and complications.

Procedure of semen collection: Semen was collected from all the cases by masturbation after abstinence for a period of minimum 3-5 days and collected in a wide mouthed polypropylene bottle. Collected semen was sent immediately to pathology laboratory and allowed to liquefy for 30 minutes at $37^{\circ} \mathrm{c}$. Semen samples were analyzed as per the guidelines of WHO report. Semen samples were particularly analyzed for sperm count, motility and morphology. Samples were collected preoperatively and postoperatively at the end of $3^{\text {rd }}$ month and $6^{\text {th }}$ month and further analyzed.

\section{Definitions}

Oligozoospermia: Sperm counts < 20 million/ml.

Asthenozoospermia: In cases whose sperm motility was
$<50 \%$.

Teratozoospermia: Cases with identified morphological defects in the sperms either at head or tail or midpiece or all parts. ${ }^{4}$

\section{Procedure of color Doppler}

All the cases were examined by Toshiba color Doppler ultrasound scanner in supine position. Examination was performed at the level of the inguinal canal and over the superior lateral edge of the testis or posterior lateral edge in large varicocele. The diameter of the testicular veins was measured during rest and in Valsalva maneuver by using linear array transducer. If the diameter of the testicular veins is $>2.5 \mathrm{~mm}$ at rest, was considered as a varicocele. After varicocelectomy of four weeks, a Doppler Ultrasonography imaging was performed to confirm the improvement of varicocele by absence of venous back flow.

\section{STATISTICAL ANALYSIS}

All the data was collected and entered into Microsoft excel spread sheet. The corrected data was analyzed with SPSS software version 20 for windows 10 and level of significance was assessed by paired $t$ test, by considering $p$ value less than 0.05 .

\section{RESULTS}

A total of 135 patients were selected in the study based on the inclusion criteria and 125 participated in the study and 10 cases data could not be followed postoperatively. Majority $45.6 \%$ of cases were from the age group of $18-25$ years followed in order by $26-35$ years (32.8\%) and $36-45$ years (21.6\%). [Figure-1] The mean age of the study group was $25.12 \pm 1.2$ years.

Table-1 summarizes the types of varicocele, distribution of varicocele side and grading of the clinical varicocele. Majority (84.8\%) had an isolated left sided varicocele with 18 cases of subclinical varicocele, 42 cases of grade-III varicocele, 25 cases of grade-II and 21 cases of Grade-I. In the study 15 cases of Bilateral varicocele were observed with subclinical 7 cases ( 7 on the left side only), Grade-III varicocele in 2 cases and grade-II in 6 cases. Isolated right sided varicocele was observed in 4 cases only (3.2\%) with 1 cases of subclinical varicocele and 3 cases of Grade-II varicocele. In our study 26 cases $(20.8 \%)$ of subclinical varicocele were identified and 99 cases $(79.2 \%)$ of clinical varicocele.

Figure-2 represents the type of semen abnormality in all the cases of the study. All the cases were identified with oligozoospermia (100\%) whereas 34 patients with Asthenozoospermia, oligoasthenospermia and 21 cases with Teratozoospermia, oligoasthenoteratozoospermia and Asthenoteratozoospermia.

\section{Effects of sperm concentration and motility after Varicocelectomy}

Table-3 summarizes the characters of semen parameters in the cases preoperatively and postoperatively. In all the cases of Oligozoospermia preoperatively, 32 cases had sperm count $<5$ Million/ml with a mean value of $2.8 \pm 2.6$ (Mean \pm SD), 67 cases with $6-10$ million/ $\mathrm{ml}$ with a mean of $7.2 \pm$ 1.9 and 26 cases had sperm count in range of $11-14$ million/ 
$\mathrm{ml}$ and mean of $13.2 \pm 1.9$. During the first follow up in these cases a statistically significant increase in the sperm

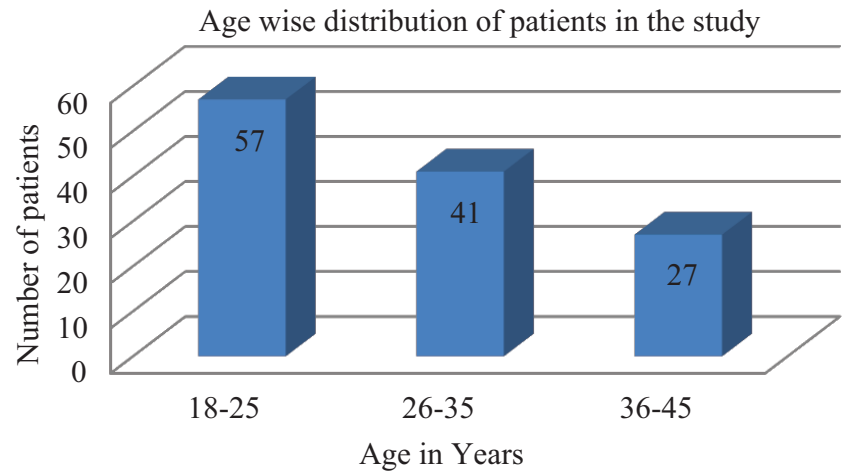

Figure-1: Age wise distribution of patients in the study

\begin{tabular}{|l|c|l|c|}
\hline Side of Varicocele & $\begin{array}{c}\text { No of } \\
\text { patients }\end{array}$ & Grade of Varicocele & $\%$ \\
\hline Isolated left & 106 & $\begin{array}{l}\text { Grade-I- 21 } \\
\text { Grade-II -25 } \\
\text { Grade-III-42 } \\
\text { Subclinical-18 }\end{array}$ & 84.8 \\
\hline Isolated right & 4 & $\begin{array}{l}\text { Grade-II-3 } \\
\text { subclinical-1 }\end{array}$ & 3.2 \\
\hline Bilateral & 15 & $\begin{array}{l}\text { Grade-II-6 } \\
\text { Grade-III- 2 } \\
\text { subclinical-7 }\end{array}$ & 12 \\
\hline Table-1: Distribution of patients by side and grade of varico- \\
cele
\end{tabular}

count was observed in all the cases with a mean increase of $14.1 \pm 2.8$ in cases with $<5$ Million/ $\mathrm{ml}, 21.14 \pm 3.5$ in cases with $6-10$ million $/ \mathrm{ml}$ and $32.24 \pm 3.5$ in cases with $11-14$ million/ml ( $\mathrm{p}$ value $<0.01$ ) among cases with both clinical and subclinical varicocele. During the $2^{\text {nd }}$ follow up in all the cases a statistically significant increase was observed in all the cases with highest in cases with 11-14 million/ml and with mean increase of $41.37 \pm 2.7$. (Mean $\pm \mathrm{SD}$ ).

However with regard to 34 cases of Asthenozoospermia, a statistically significant improvement was observed in 26

Distribution of patients by preoperative semen parameters

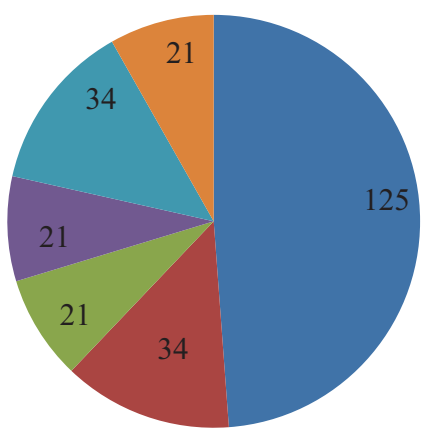

-Oligospermia =Oligoasthenoteratozoosp ermia

- Asthenospermia -Oligoasthenospermia

- Teratozoospermia asthenoteratozoospermia

Figure-2: Distribution of patients by preoperative semen parameters

\begin{tabular}{|c|c|c|c|c|c|c|}
\hline \multirow[t]{2}{*}{ Sperm concentration (Million/ml) } & \multirow{2}{*}{$\begin{array}{c}\text { No of } \\
\text { patients }\end{array}$} & \multirow{2}{*}{$\begin{array}{l}\text { Preoperative } \\
\text { (Mean } \pm \text { SD) }\end{array}$} & \multicolumn{4}{|c|}{ Post operative follow up } \\
\hline & & & $\begin{array}{c}\text { 1st } \\
\text { follow-up }\end{array}$ & P value & $\begin{array}{l}\text { 2nd Follow } \\
\text { up }\end{array}$ & P Value \\
\hline \multicolumn{7}{|l|}{ All patients $=125$} \\
\hline$<5$ Million/ml & 32 & $2.8 \pm 2.6$ & $14.1 \pm 2.8$ & $<0.01$ & $24.1 \pm 1.8$ & $<0.01$ \\
\hline 6-10 million/ml & 67 & $7.2 \pm 1.9$ & $21.14 \pm 3.5$ & $<0.01$ & $33.41 \pm 2.5$ & $<0.01$ \\
\hline 11-14 million/ml & 26 & $13.2 \pm 1.9$ & $32.24 \pm 3.5$ & $<0.01$ & $41.37 \pm 2.7$ & $<0.01$ \\
\hline \multicolumn{7}{|l|}{ Asthenozoospermia=34 } \\
\hline$<5$ Million/ml & 7 & $11.1 \pm 3.6$ & $28.10 \pm 1.9$ & $<0.01$ & $32.14 \pm 3.2$ & $<0.01$ \\
\hline 6-10 million/ml & 19 & $21.1 \pm 5.6$ & $42.14 \pm 2.4$ & $<0.01$ & $45.14 \pm 2.1$ & $<0.01$ \\
\hline 11-14 million/ml & 8 & $24.5 \pm 1.8$ & $45.14 \pm 3.8$ & $<0.01$ & $49.21 \pm 2.3$ & $<0.01$ \\
\hline
\end{tabular}

\begin{tabular}{|c|c|c|c|c|c|}
\hline \multirow[t]{2}{*}{ Semen Parameter } & \multirow{2}{*}{$\begin{array}{l}\text { Preoperative } \\
\text { (Mean } \pm \text { SD) }\end{array}$} & \multicolumn{4}{|c|}{ Post operative follow-up } \\
\hline & & 1st follow-up & $P$ value & 2nd Follow up & P Value \\
\hline \multicolumn{6}{|l|}{ Teratozoospermia $(n=9)$} \\
\hline Sperm Morphology (\%) & $1.3 \pm 2.1$ & $5.24 \pm 2.3$ & $<0.01$ & $11.21 \pm 2.6$ & $<0.01$ \\
\hline \multicolumn{6}{|c|}{ Oligoasthenoteratozoospermia $(\mathrm{n}=21)$} \\
\hline Sperm Morphology (\%) & $1.3 \pm 2.1$ & $6.6 \pm 3.8$ & $<0.01$ & $8.5 \pm 1.8$ & $<0.05$ \\
\hline Sperm concentration (million/ml) & $4.8 \pm 2.9$ & $12.4 \pm 9.4$ & $<0.01$ & $22.4 \pm 10.1$ & $<0.001$ \\
\hline Sperm motility (\%) & $14.1 \pm 9.21$ & $28.1 \pm 10.1$ & $<0.01$ & $40.1 \pm 9.9$ & $<0.01$ \\
\hline \multicolumn{6}{|l|}{ Oligoasthenospermia $(n=34)$} \\
\hline Sperm concentration (million/ml) & $8.4 \pm 3.1$ & $28.1 \pm 2.8$ & $<0.01$ & $38.1 \pm 4.2$ & $<0.001$ \\
\hline Sperm motility (\%) & $26.1 \pm 4.2$ & $36.1 \pm 3.4$ & $<0.01$ & $42.1 \pm 4.1$ & $<0.001$ \\
\hline \multicolumn{6}{|l|}{ asthenoteratozoospermia $(n=21)$} \\
\hline Sperm Morphology (\%) & $1.3 \pm 2.1$ & $6.6 \pm 3.8$ & $<0.01$ & $8.5 \pm 1.8$ & $<0.01$ \\
\hline Sperm motility (\%) & $5.8 \pm 2.1$ & $12.4 \pm 9.4$ & $<0.01$ & $38.1 \pm 6.9$ & $<0.01$ \\
\hline
\end{tabular}


cases during the first follow up with a mean increase of 45.14 \pm 3.8 (Mean $\pm \mathrm{SD})$ and in all the cases during the second follow up. The results were found to be statistically significant when compared in all the cases during both the follow ups. ( $\mathrm{P}$ value $<0.01)$ [Table-3]

\section{Effects of Varicocelectomy in patients with abnormal sperm morphology}

The mean of the sperm morphology in teratozoospermic patients $(n=9)$ was $1.3 \pm 2.1 \%$ and in all the cases during $1^{\text {st }}$ follow up there was a significant increase to $5.24 \pm 2.3 \%$ and $11.21 \pm 2.6 \%$ during second follow up after surgical repair in all the cases of clinical and subclinical varicocele.

In our study 21 cases had oligoasthenoteratozoospermia, in 16 cases sperm concentration and sperm motility increased during first follow up with a mean increase of $28.1 \pm 10.1 \%$ in sperm motility and $12.4 \pm 9.4 \%$ in sperm concentration. All the three parameters were increased in all the 21 cases during the $2^{\text {nd }}$ follow up with mean increase of $8.5 \pm 1.8 \%$ in sperm morphology, $22.4 \pm 10.1 \%$ in sperm concentration and $40.1 \pm$ $9.9 \%$ in sperm motility. There was a statistically significant increase in all the parameters during $1^{\text {st }}$ and $2^{\text {nd }}$ follow up after surgical repair. ('P'value $<0.001$ )

Among 34 cases of oligoasthenozoospermia, 26 cases showed improvement in both parameters (Sperm concentration and motility) with mean improvement of $28.1 \pm 2.8 \%$ in sperm concentration during $1^{\text {st }}$ follow up and $38.1 \pm 4.2 \%$ in $2^{\text {nd }}$ follow up, Sperm motility was increased by $36.1 \pm 3.4 \%$ in $1^{\text {st }}$ follow up and $42.1 \pm 4.1 \%$ in $2^{\text {nd }}$ follow up and was found statistically significant. In rest of 6 cases, 4 demonstrated increase of sperm motility only in $1^{\text {st }}$ follow up and 2 cases only in sperm concentration but both parameters were increased in $2^{\text {nd }}$ follow up in all the 6 cases. [Table-4] In 21 cases of Asthenoteratozoospermia, 17 cases demonstrated increase of sperm morphology and motility in $1^{\text {st }}$ follow up whereas 4 cases demonstrated rise of sperm morphology and motility during $2^{\text {nd }}$ follow up and all the four were cases of subclinical varicocele.

Overall results summarize that in our study a highly significant increase in sperm count was noticed in clinical and subclinical varicocele after varicocelectomy, but there was no significant difference in sperm morphology in both the groups. However regarding sperm motility a significant increase in sperm motility was observed in clinical varicocele and subclinical varicocele but the significant increase was less in subclinical than clinical varicocele.

\section{DISCUSSION}

Varicocele is describes as one of the most common causes of male infertility and the mechanism for infertility are still a debate and much thorough and deeper studies are required in obtaining a clear evidence. Our study clearly identified the abnormal seminal parameters with particular reference to sperm concentration, motility and morphology in cases of clinical and subclinical varicocele. Few studies reported after surgical repair the improvement of parameters to normal but few studies report improvement only in sperm concentration than motility and morphology. A meta analysis report by Damsgaard J et al analyzed various studies and reported an increase in sperm count after sub inguinal varicocelectomy. ${ }^{5}$
In the present study the maximum age group of $18-25$ years and mean age was $25.12 \pm 1.2$ years which is similar to the report in the study of Mulhall JP. ${ }^{6}$ Universally many of the studies reported that left side varicocele is commonest which is also observed in the present study. In the present study, preoperatively all the cases were oligozoospermic and were categorised into three categories with < 5 Million/ml, 6-10 million/ml and 11-14 million/ $\mathrm{ml}$. In all these cases there was a significant increase in the sperm concentration in clinical and subclinical cases of varicocele which corresponds with the findings of the studies of Schlesinger $M$ et al who reported the same findings in his study. ${ }^{7}$ The mean increase in sperm concentration was $16.1 \mathrm{million} / \mathrm{ml}$ overall which is similar to findings of A.Agarwal et al. ${ }^{8}$ cayan et al in his study observed that after sub inguinal varicocelectomy the increase in sperm motility was $34.2 \%$ when compared preoperatively with $26.2 \% .^{9}$

In the present study, motile sperm concentration has increased from $14.1 \%$ preoperatively to $40.2 \%$ after surgical repair in both clinical and subclinical varicocele. However findings of Jarow JP et al in their studies reported that increase in the sperm motility is dependable on the size of the varicocele and reported no increase in sperm motility in subclinical varicocele. This is contrary to the findings of our study. ${ }^{10}$ In the present study a significant increase in the Sperm morphology was identified and mean increase of $11.21 \%$ in clinical and subclinical cases of varicocele after repair. However findings of our study were in contrary to the findings of Okeke and his team who reported a nonsignificant change in sperm morphology in subclinical cases and indicated that varicocelectomy is not indicated in teratozoospermia. ${ }^{11}$ Our findings suggested that cases of Asthenozoospermia and Teratozoospermia could respond well in sperm motility and concentration in clinical cases as well as subclinical cases of varicocele after surgical repair. But Maciejko and his co-workers proposed that neither Asthenozoospermia nor Teratozoospermia improved in subclinical cases. ${ }^{12}$

In our total study population, $4.5 \%$ of cases had a recurrence of varicocele and 3.5\% developed secondary hydrocele as postoperative complications which were similar to the findings of McGarry $\mathrm{P}$ in his study. ${ }^{13}$ Few of the studies reported that sperm concentration and morphology was not increased after varicocelectomy up to six months period in clinical cases and the results of these studies were statistically insignificant.

To conclude our study demonstrated a clear increase in the semen parameters, i.e., sperm morphology, concentration and motility in clinical and subclinical cases of varicocele after surgical repair. Findings of our study were similar to one of the study in Tamilnadu, India who also reported a significant increase of sperm concentration, average sperm motility and morphology postoperatively. ${ }^{14}$ Our study helps the surgeons in taking a decision in cases of clinical and subclinical varicocele among cases of infertility with varicocele as a prime factor. Our study can suggest that Varicocele repair can allow IVF/ICSI without testicular sperm aspiration or extraction, and this suggests that varicocele repair provides meaningful improvement not only to obviate the need for 
assisted reproductive technique (ART), but also to downstage or shift the level of ART against male factor infertility.

\section{REFERENCES}

1. Kibar Y, Seckin B, and Erduran D: The effects of subinguinal varicocelectomy on Kruger morphology and semen parameters J Urol 2002;168(3): 1071-1074.

2. Kumar Rajeev, Shah Rupin. Varicocele and male infertility: current status. J Obstet Gynecol India 2005;55(6):505-516.

3. World health organization. The influence of varicocele on parameters of infertility in a large group of men presenting to infertility clinics. Fertil.steril. 1992;57(2):1289-1293.

4. WHO Laboratory Manual for the Examination of Human Semen and Sperm-Cervical Mucus Interaction, Cambridge University Press, Cambridge, UK, 5th edition, 2010.

5. Damsgaard J, Joensen UN, Carlsen E, Erenpreiss J, Blomberg Jensen M, Matulevicius V, et al. Varicocele is associated with impaired semen quality and reproductive hormone levels: a study of 7035 healthy young men from six European countries. Eur Urol 2016;70(3): 1019-29.

6. Mulhall JP, Stalh PJ, Stember D; Varicocele, Clin Care Path. Androl, (2013): p 165-70.

7. SchlesingerM. H. Wilets I. F. Nagler H. M. Treatment outcome after varicocelectomy: a critical analysis, Urologic Clinics of North America. 1994; 21(5): 517 529.

8. A. Agarwal, F. Deepinder, M. Cocuzza et al. Efficacy of varicocelectomy in improving semen parameters: new meta-analytical approach. Urology 2007;70(3): 532-538.

9. Cayan S, Shavakhabov S, Kadioğlu A. Treatment of Palpable Varicocele in Infertile Men: A Metaanalysis to Define the Best Technique. J of Andrology. 2009;30(2):33-40.

10. Jarow JP, Ogle SR, Eskew LA. Seminal improvement following repair of ultrasound detected subclinical varicoceles. J Urol. 1996;155(4):1287-90.

11. Okeke L, Ikuerowo O, Chiekwe I, et al, Is varicocelectomy indicated in subfertile men with clinical varicoceles who have asthenospermia or teratospermia and normal sperm density? International Journal of Urology 2007;14(8).729-732.

12. Maciejko A., Kim P., Jang T., et al. Isolated teratospermia: is varicocelectomy indicated? Journal of Urology 2005;173(4):369.

13. McGarry P, Alrabeeah K, Jarvi K, Zini A. Urology. 2015;85(2):357-62.

14. Kumar R, Sekar H, Krishnamoorthy S, Kumaresan N, Ramanan V. Analysis of Outcomes of Surgical Treatment for Varicocele in Primary Infertility Based on Seminal Parameters and Pregnancy Rate. Int J of Scientific Study. 2016;4: 205-10.

Source of Support: Nil; Conflict of Interest: None

Submitted: 25-04-2018; Accepted: 30-05-2018; Published online: 05-06-2018 